\title{
Multilateral Environmental Agreements and Environmental Technology Transfer
}

\author{
by \\ Larry D. Qiu* \\ Hong Kong University of Science and Technology \\ Zhihao Yu \\ University of Nottingham
}

This version: January 2002

\begin{abstract}
We develop a North-South model of international trade and transboundary pollution to analyze the relationship between environmental technology transfer and the South's incentive to sign a multilateral environmental agreement (MEA). First, we show that technology transfer could either increase or reduce the South's incentive to sign the MEA. Second, we show that the South's participation in the MEA would reduce the market incentive of technology transfer. Both results have very clear policy implications for (i) the sequence of technology transfer and the South's MEA membership and (ii) the legitimacy of South's subsidies for technology transfer.

General Field: $\quad$ International Trade

JEL Classification No.: F18

Key Words: $\quad$ Trade, Environment, MEAs, Environmental technology transfer
\end{abstract}

* Correspondence to: Larry D. Qiu, Department of Economics, Hong Kong University of Science and Technology, Clear Water Bay, Kowloon, Hong Kong. Tel number: +(852)2358-7628, Fax number: +(852)2358-2084, Email: larryqiu@ust.hk, Web site: http://www.bm.ust.hk/ ${ }^{2}$ larryqiu. 


\section{Introduction}

With increasing awareness of environment issues, we have witnessed the emergence of many multilateral environmental agreements (MEAs) over the past two decades. While signatory countries are expending efforts to adhere to the agreements, they are also trying hard to increase the number of signatories using various measures and opportunities. So far over 20 MEAs have included trade measures to induce nonsignatories to sign the agreements. ${ }^{1}$ However, discriminatory trade-restricting measures are neither consistent with the most-favored-nation principle of the World Trade Organization (WTO) nor are they effective. ${ }^{2}$ Instead, a view is commonly shared that nonsignatory countries, which are most likely developing countries, may not be able to afford to raise their environmental standards given their existing technologies. Accordingly, it is often recommended that positive measures and incentives, such as financial assistance and environmental technology transfer, should be used since they are more efficient and effective than punitive measures.

In this paper, we develop a North-South model of international trade and transboundary pollution to analyze formally the relationship between environmental technology transfer and the South's (a nonsignatory country) incentive to sign an MEA (formed by the North). Two questions are particularly interesting. First, will technology transfer induce the South to sign the MEA? Second, will the South's participation in the MEA increase the market incentives for technology transfer? Our model highlights the trade effects of both national environmental policy as it is the key issue that fuels the discussion about market access and competitiveness (see Bhagwati and Hudec, 1996). By signing an MEA, the South has to increase its environmental taxes from an optimal level to an MEA-specified higher level. But, in return, it receives financial transfers from the North as compensation.

We first show that the transfer of environmental technology may either raise or reduce the South's incentive to sign the MEA. On the one hand, with cleaner environmental technology due to technology transfer, the negative effect of an increase in environmental taxes on the South's welfare becomes smaller. This raises the South's incentive to sign. On the other hand, however,

\footnotetext{
${ }^{1}$ For example, the Basel Convention bans the trade in hazardous wastes with non-signatories. The Montreal Protocol also bans trade in ozone-depleting substances and products between signatories and non-signatories.

${ }^{2}$ See Hudec (1996), WTO (1996) and UNE and IISD (2000).
} 
the South's optimal environmental tax after technology transfer is found to be lower than before. Because of this, the MEA membership requires the South to depart from its optimal policy level more in the case of technology transfer than in the case of no technology transfer. Hence, the South is less reluctant to sign the MEA after receiving the better technology. The South's incentive depends on the relative importance of these two effects. An implication of this result is that the assisted environmental technology transfer by the MEA member countries should be given before a developing country becomes a signatory of the MEA if technology transfer raises the participation incentive, but it should be given after the country commits to signing the MEA if the technology transfer reduces the participation incentive.

Second, we show that the South's MEA membership reduces the market incentives for technology transfer. Participation in the MEA is the Southern government's decision, but the technology transfer involves decisions by firms in both the North and the South. Because of the financial compensation, the Southern government may be willing to sign the MEA, but the South's inclusion in the MEA means that the average pollution tax increases, which in turn means less profit gains to the firms from a technology transfer. Based on this finding, we can draw the following policy implication: Financial transfer, at least in part, should be provided to assist firms in environmental technology transfer or the South should be allowed to subsidize environmental technology transfer.

The literature on the theory of MEAs has been growing during the last decade. ${ }^{3}$ It has been concluded that carrots and sticks (e.g., financial assistance and technology transfers as carrots and sanctions as sticks) are needed to induce countries to become signatories of MEAs and to stabilize MEAs (see Barrett, 1997a \& b). The use of trade sanctions is based on the idea of an "issue-linkage" to enforce MEAs and that of monetary transfers is based on the principle of "gainers compensate losers". Technology transfers are also considered to be vital, especially for developing countries, because they simply may not have access to the necessary technology on favorable terms (Charnovitz, 1993; WTO, 1996). However, to our knowledge, our study is the first to provide a formal analysis of how environmental technology transfer affects developing countries' incentives to sign MEAs and how participation in an MEA affects the market incentive for environmental technology transfer.

\footnotetext{
${ }^{3}$ See Hoel (1992), Carraro and Siniscalco (1993, 1994), Heal (1993), and Barrett (1994b, 1997a, 1997b), among others.
} 
We focus on pollution tax as the environmental policy in this paper. In a model with imperfect competition in the product market, such policies have the same effects as more familiar strategic trade policies. Barrett (1994a), Kennedy (1994), Conrad (1996), and Ulph (1996) provide useful analyses on strategic environmental policies in various contexts. However, none of these studies deals with environmental technology transfers or MEA-related issues. Our paper explores these issues in a model of imperfect competition.

The rest of this paper is organized as follows. Section 2 develops the model without MEAs and analyzes the equilibrium. Section 3 introduces MEAs to the model and provides an analysis, together with a numerical example, of the relationship between technology transfer and MEA participation. Section 4 includes some concluding remarks.

\section{The Model}

Assume that there are two countries, called the North (representing a developed country) and the South (representing a developing country), respectively. There is just one firm in each country: we call the firm located in the North the N-firm and that in the South the S-firm. These firms produce an homogenous product. Production of this product emits pollution. However, the N-firm has cleaner technology than the S-firm in the sense that the pollution content (i.e., the amount of pollutant generated when producing one unit of output) of the N-firm, denoted $e_{n}$, is lower than that of the $\mathrm{S}$-firm, denoted $e_{s}$, i.e., $e_{n}<e_{s}$. The firms are otherwise identical. The $\mathrm{N}$-firm could license its technology to the S-firm, and if it does, the S-firm's pollution content will be reduced to $e_{n} \cdot{ }^{4}$ The Northern government imposes an environmental tax, denoted $t_{n}$, on each unit of pollution generated by the N-firm. The corresponding tax imposed by the Southern government is assumed to be $t_{s}$. To emphasize the policy effects on people's disutility and their strategic aspects, we assume that the firms sell their products to a third market. This allows us to put aside the often-considered changes in consumer surplus resulting from price changes. Assume linear demand, $p=1-\left(q_{n}+q_{s}\right)$, where $q_{i}(i=n, s)$ is the output of the i-firm. For simplicity, assume that the firms have constant marginal cost of production and without loss of generality, assume this cost to be zero. The firms compete in quantity (i.e., in Cournot fashion).

\footnotetext{
${ }^{4}$ It has been argued that prior to technology transfer, the N-firm must spend some effort/money, $c$, to make the technology suitable for the S-firm. We included this sunk cost in an earlier version of this paper and found no qualitative changes in any of the results.
} 
We consider the following sequence of moves. In the first stage, the N-firm makes its licensing decision and the firms together decide on the licensing fee. In the second stage, both governments set their respective tax policies, in a non-cooperative way. In the final stage, the firms produce and compete in the product market. We will derive and analyze the subgame perfect Nash equilibrium (SPNE).

It is worth stressing that in contrast to most studies (with the exception of Ulph, 1996), we assume that the governments move in the second stage. By this, we do not intend to argue that governments can never make earlier commitments before the firms' technology transfer decision, but we have two reasons for considering this sequence. First, once technology is transferred, it is irreversible, but the governments can always change their policies. Second, the world is now in an era in which countries are negotiating about the environmental issues and these negotiations will surely lead to changes in environmental policies in the near future. Anticipating this, firms may act earlier before the policy changes. We seek to examine how the firms behave in this regard and how their decisions affect future policy changes.

\subsection{A subgame without technology transfer}

In this subsection, we focus on the subgame perfect equilibrium in which there is no technology transfer in the first stage. Given any tax policies, $t=\left\{t_{n}, t_{s}\right\}$, of the second stage, each firm's profit function is given as $\pi_{i}=\left(p-t_{i} e_{i}\right) q_{i}$ and the equilibrium output and profits are $q_{i}^{0}=\left(1-2 t_{i} e_{i}+t_{j} e_{j}\right) / 3$ and $\pi_{i}^{0}=\left(1-2 t_{i} e_{i}+t_{j} e_{j}\right)^{2} / 9$, respectively, where and hereafter superscript 0 denotes no technology transfer. In this case, $q_{i}^{0}$ and $\pi_{i}^{0}$ constitute the third-stage equilibrium.

A country's welfare is equal to the sum of its firm's profit, the pollution disutility for its population and tax revenue:

$$
W_{i}^{0}=\pi_{i}^{0}-D_{i}\left(q_{i}^{0} e_{i}+\gamma q_{j}^{0} e_{j}\right)+t_{i} e_{i} q_{i}^{0}
$$

where $\gamma \in(0,1)$ measures the degree of transboundary pollution and the disutility function, $D_{i}(\cdot)$, has the following properties: $D_{i}>0, D_{i}^{\prime}>0$ and $D_{i}^{\prime \prime} \geq 0$.

We now analyze the second stage game, in which each government chooses its tax policy to maximize its country's welfare, $W_{i}^{0}$. Note the first-order derivative is ${ }^{5}$

\footnotetext{
${ }^{5}$ Given $D_{i}^{\prime \prime} \geq 0$, it is straightforward to verify the second-order and stability conditions for optimal policies: $\partial^{2} W_{i} / \partial t_{i}^{2}<0$ and $\left(\partial^{2} W_{n} / \partial t_{n}^{2}\right)\left(\partial^{2} W_{s} / \partial t_{s}^{2}\right)-\left(\partial^{2} W_{n} / \partial t_{s} \partial t_{n}\right)\left(\partial^{2} W_{s} / \partial t_{n} \partial t_{s}\right)>0$.
} 


$$
\frac{\partial W_{i}^{0}}{\partial t_{i}}=\frac{\partial\left(\pi_{i}^{0}+t_{i} e_{i} q_{i}^{0}\right)}{\partial t_{i}}-\frac{\partial\left(e_{i} q_{i}^{0}+\gamma e_{j} q_{j}^{0}\right)}{\partial t_{i}} D_{i}^{\prime}, \quad i, j=n, s, i \neq j .
$$

The first term then is negative, suggesting that each government tends to provide a subsidy $\left(t_{i}<0\right)$. This is the familiar strategic profit-shifting incentive. However, each government also has the incentive to discourage production in order to reduce pollution. This incentive is captured by the second term of (2). If $\left[\partial\left(e_{i} q_{i}^{0}+\gamma e_{j} q_{j}^{0}\right) / \partial t_{i}\right]<0$, i.e., the total pollution in country $i$ decreases as $t_{i}$ increases, then the second term is positive and thus the government of this country has an incentive to raise $t_{i}$. We refer to this as the pollution-reducing incentive. The final outcome of the policy, i.e., whether $t_{i}$ is positive (tax) or negative (subsidy), depends upon the relative degrees of the pollution-reducing incentive and the profit-shifting incentive. However, for sufficiently strong transboundary pollution, $\left[\partial\left(e_{i} q_{i}^{0}+\gamma e_{j} q_{j}^{0}\right) / \partial t_{i}\right]$ is not necessarily negative because $\partial q_{j}^{0} / \partial t_{i}>0$. For example, note that since the North's tax encourages the S-firm's production while it discourages the N-firm's production, an increase in the North's tax may not be able to reduce the total pollution level in the North. That is, $\partial\left(e_{n} q_{n}^{0}+\gamma e_{s} q_{s}^{0}\right) / \partial t_{n}$ may be positive. In this case, the pollution-reducing incentive moves in line with the profit-shifting incentive, always calling for a subsidy in the North.

To make the analysis as clear as possible, we focus on a special disutility function from now on: $D_{i}(x)=\beta_{i} x$, where parameter $\beta_{i}$ captures regional difference regarding pollution disutility. Assume $\beta_{n}>\beta_{s}>0 .{ }^{6}$ Then, setting $\partial W_{i}^{0} / \partial t_{i}=0$ from (2) gives the first-order condition for optimization, from which we can derive each government's policy reaction function:

$$
t_{i}\left(t_{j}\right)=\frac{1}{4 e_{i}}\left[3\left(2 e_{i}-\gamma e_{j}\right) \beta_{i}-e_{j} t_{j}-1\right], \quad i, j=n, s \text { and } i \neq j .
$$

The two reaction curves, $R_{n}^{0}$ and $R_{s}^{0}$, are depicted in Figure 1. It is straightforward to compute the equilibrium policies, denoted $t_{n}^{0}$ and $t_{s}^{0}$,

$$
t_{i}^{0}=\frac{1}{5 e_{i}}\left[4\left(2 e_{i}-\gamma e_{j}\right) \beta_{i}-\left(2 e_{j}-\gamma e_{i}\right) \beta_{j}-1\right]=\frac{1}{5 e_{i}}\left[\left(8 \beta_{i}+\gamma \beta_{j}\right) e_{i}-2\left(\beta_{j}+2 \gamma \beta_{i}\right) e_{j}-1\right] .
$$

Some interesting properties of the above equilibrium policies shall be particularly helpful in

\footnotetext{
${ }^{6}$ Many factors may give rise to this assumption, for example, that the North has higher income than the South, or that people in the North have stronger environmental awareness than do those in the South.
} 
understanding the main results in the paper and therefore they are summarized in the following lemma:

Lemma 1: The equilibrium environmental taxes in the case of no technology transfer have the following properties:

$$
\text { (i) } \frac{\partial t_{i}^{0}}{\partial \beta_{i}}>0, \frac{\partial t_{i}^{0}}{\partial \beta_{j}}<0 ;(i i) \frac{\partial t_{i}^{0}}{\partial e_{i}}>0, \frac{\partial t_{i}^{0}}{\partial e_{j}}<0 ;(i i i) \frac{\partial t_{n}^{0}}{\partial \gamma}<0
$$

Proof: First, based on (4), we obtain $\partial t_{i}^{0} / \partial \beta_{i}=4\left(2 e_{i}-\gamma e_{j}\right) / 5 e_{i}$. It is obviously positive for $i=s$. For $i=n$, we also have $2 e_{n}-\gamma e_{s}>0$ since we will impose a condition, C1(i), later in this section to ensure that the optimal policy in each country is indeed taxation. Second, and for the same reason, we obtain $\partial t_{i}^{0} / \partial \beta_{j}=-\left(2 e_{j}-\gamma e_{i}\right) / 5 e_{i}<0$. Third, $\partial t_{i}^{0} / \partial e_{i}=\left(1+2 e_{j} \beta_{j}+\right.$ $\left.4 \gamma e_{j} \beta_{i}\right) / 5 e_{i}^{2}>0$ and $\partial t_{i}^{0} / \partial e_{j}=-\left(\beta_{j}+2 \gamma \beta_{i}\right) / 5 e_{i}<0$. Finally, $\partial t_{n}^{0} / \partial \gamma=\left(e_{n} \beta_{s}-4 e_{s} \beta_{n}\right) / 5 e_{n}<0$ because $e_{n}<e_{s}$ and $\beta_{s}<\beta_{n}$.

$<$ Figure 1 about here $>$

The intuitions behind these results are as follows. First, we discuss the effect of $\beta_{i}$ on equilibrium pollution taxes. The result of $\partial t_{i}^{0} / \partial \beta_{i}>0$ is straightforward since (marginal) pollution damage is higher when $\beta_{i}$ goes up. The result of $\partial t_{i}^{0} / \partial \beta_{j}<0$ comes from the fact that the policy (pollution taxes) reaction functions are downward-sloping, i.e., the policies are strategic substitutes. Therefore, a larger $\beta_{j}$ leads to a higher tax in country $j$, which in turn results in a lower tax in country $i$. These two inequalities together suggest that if the two countries are different only because the North has higher marginal pollution damage than the South has (i.e., $\beta_{n}>\beta_{s}$ ), then the North will set a higher tax than the South (i.e., $t_{n}^{0}>t_{s}^{0}$ ).

Second, the effect of $e_{i}$ on equilibrium pollution taxes can be illustrated as follows. For example, a reduction of $e_{s}$ would shift the Northern government's reaction curve outward to $R_{n}^{T}$ [since $\partial t_{n} / \partial e_{s}=-\left(3 \gamma \beta_{n}+t_{s}\right) / 4 e_{n}<0$ from (3)] but would shift the Southern government's reaction curve inward to $R_{s}^{T},{ }^{7}$ and we therefore have $\partial t_{i}^{0} / \partial e_{i}>0$ and $\partial t_{i}^{0} / \partial e_{j}<0$ (see Figure

\footnotetext{
${ }^{7}$ To see this, note that from the reaction function, $\partial t_{s} / \partial e_{s}=\left\{6 \beta_{n} e_{s}-\left[3\left(2 e_{s}-\gamma e_{n}\right) \beta_{s}-e_{n} t_{n}-1\right]\right\} / 4 e_{s}^{2}=$ $\left(3 \beta_{s}-2 t_{s}\right) / 2 e_{s}$. The maximum for $t_{s}$ is when $e_{s}=0$, at which, from the Southern government's reaction function, $t_{s}=\left[3\left(2 e_{s}-\gamma e_{n}\right) \beta_{s}-1\right] / 4 e_{s}$, which is smaller than $3 \beta_{s} / 2$. Hence, $t_{s}<3 \beta_{s} / 2$ for all $t_{s}$, and so $\partial t_{s} / \partial e_{s}>0$.
} 
1). The inequality $\partial t_{i}^{0} / \partial e_{i}>0$ indicates that a country will lower its tax if its firm becomes more efficient. Notice that $\partial t_{i}^{0} / \partial e_{i}$ can be decomposed into two parts, $\left(1+2 e_{j} \beta_{j}\right) / 5 e_{i}^{2}$ and $4 \gamma e_{j} \beta_{i} / 5 e_{i}^{2}$ (see the proof), and both are positive. The first part is associated with the strategic effect of "profit-shifting" and the second part is associated with the transboundary effect of "carbon leakage". The strategic effect is similar to a well-known result in the strategic trade literature, that is, "subsidies" should be higher for more efficient firms (Neary, 1994). A lower environmental tax here plays the role of a "subsidy" to the domestic firm. On the other hand, the North also cares about the pollution generated by the South using the less-efficient technology, called "carbon leakage" in some situations. With a more-efficient technology, the North would benefit from a lower pollution tax simply because it would discourage production (and hence pollution) in the South. The results of $\partial t_{i}^{0} / \partial e_{j}<0$ can be understood similarly.

Parts (i) and (ii) of Lemma 1 suggest that if $\beta_{n}$ is sufficiently larger than $\beta_{s}$ (e.g., due to the income effect), the pollution tax in the North will be higher even though it has more efficient technology. We assume that this is the case for our analysis.

Finally, the intuition for the result of $\partial t_{n}^{0} / \partial \gamma<0$ is again associated with the transboundary effect of carbon leakage. When transboundary pollution becomes severe ( $\gamma$ is larger), the North would lower its pollution tax to discourage production in the South. The effect of such a move on the Southern policy $\left(\partial t_{s}^{0} / \partial \gamma\right)$, however, is ambiguous. The difference stems from the fact that the North has cleaner technology than the South (hence the North has a stronger incentive to lower the tax) and the two polices are strategic substitutes.

We now restrict the parameters values so that observed outcomes are attained: $t_{i}^{0}>0$ and $t_{n}^{0}>t_{s}^{0}$. Outcome $t_{i}^{0}>0$ basically says that the profit-shifting incentive is dominated by the pollution-reducing incentive in both countries. As a result, this model differs from many others that emphasize the strategic role of environmental policies. This condition also translates to the following conditions on the parameters (given that $e_{n}<e_{s}$ ) and therefore we assume

$$
\text { C1: (i). } \frac{1}{2} \gamma e_{s}<e_{n} \text { and (ii). } \frac{1+\left(2 e_{j}-\gamma e_{i}\right) \beta_{j}}{4\left(2 e_{i}-\gamma e_{j}\right)}<\beta_{i}<\frac{4\left(2 e_{j}-\gamma e_{i}\right) \beta_{j}-1}{\left(2 e_{i}-\gamma e_{j}\right)} .
$$

The above conditions can be easily interpreted. C1(i) shows that the transboundary pollution should not be too serious because otherwise the North may actually subsidize its firm (referring to the property $\left.\partial t_{n}^{0} / \partial \gamma<0\right)$. In light of this, we further assume $\gamma<1 / 2$. The first inequality in $\mathrm{C} 1$ (ii) says that $\beta_{i}$ needs to be sufficiently large so that the pollution-reducing incentive 
dominates the profit-shifting incentive (referring to $\partial t_{i}^{0} / \partial \beta_{i}>0$ ). However, if $\beta_{i}$ is too large, the other country may end up subsidizing its firm due to strategic substitutes of the policies (referring to $\partial t_{j}^{0} / \partial \beta_{i}<0$ ). This can be avoided by the second inequality of C1(ii). C1(ii) also implies $\beta_{i}>1 / 3\left(2 e_{i}-\gamma e_{j}\right)$.

For $t_{n}^{0}>t_{s}^{0}$ to be the outcome, we impose the necessary and sufficient condition:

$$
\text { C2: }(8-\gamma)\left(\beta_{n}-\beta_{s}\right) e_{n} e_{s}>2\left[\left(\beta_{s}+2 \gamma \beta_{n}\right) e_{s}^{2}-\left(\beta_{n}+2 \gamma \beta_{s}\right) e_{n}^{2}\right]+\left(e_{s}-e_{n}\right) .
$$

Basically, $\mathrm{C} 2$ is more likely to be satisfied by a larger $\beta_{n}-\beta_{s}$, a smaller $e_{s}-e_{n}$ and a smaller $\gamma$. To see why, we first set $\gamma=0$ in order to focus on the effects of the technology and the preference. C2 reduces to $2 e_{n}\left(\beta_{n}-\beta_{s}\right)\left(4 e_{s}+e_{n}\right)>\left(e_{s}-e_{n}\right)\left[2 \beta_{s}\left(e_{n}+e_{s}\right)+1\right]$, which is more likely to hold for a larger difference between $\beta_{n}$ and $\beta_{s}$ and a smaller difference between $e_{s}$ and $e_{n}$. According to Lemma 1 , a larger $\beta_{n}$ (for given $\beta_{s}$ ) increases $t_{n}^{0}$ and decreases $t_{s}^{0}$, while a smaller $e_{s}$ (for given $e_{n}$ ) also increases $t_{n}^{0}$ and decreases $t_{s}^{0}$.

We next focus on the effect of $\gamma$. Note that the LHS of C2 is decreasing with $\gamma$ but the RHS is increasing with $\gamma\left(\partial \mathrm{RHS} / \partial \gamma=4\left(\beta_{n} e_{s}^{2}-\beta_{s} e_{n}^{2}\right)>0\right)$. Hence, C2 is less likely to hold for a larger $\gamma$. Recall the effect of $\gamma$ on the equilibrium policies discussed above: an increase in $\gamma$ results in a smaller $t_{n}^{0}$, but the effect on $t_{s}^{0}$ is ambiguous. If it results in a larger $t_{s}^{0}$, then obviously the inequality $t_{n}^{0}>t_{s}^{0}$ becomes less likely to hold. If, however, an increase in $\gamma$ also results in a smaller $t_{s}^{0}$, the reduction of $t_{s}^{0}$ is smaller than that of $t_{n}^{0}$, because $\partial\left(t_{n}^{0}-t_{s}^{0}\right) / \partial \gamma=3 \beta_{n}\left(e_{n}-e_{s}\right) / 5 e_{n}<0$. Therefore, the inequality $t_{n}^{0}>t_{s}^{0}$ is also less likely to hold.

\subsection{A subgame with technology transfer}

We now turn to derivation of the SPNE in which technology transfer takes place in the first stage. Assume that the license fee, $f$, cannot be made contingent on the second-stage government policies. The fee is completely specified and the S-firm pays it to the N-firm before the secondstage game begins. Then, given $\{t, f\}$, the firms' profit functions are $\pi_{n}=\left(p-t_{n} e_{n}\right) q_{n}+f$ and $\pi_{s}=\left(p-t_{s} e_{n}\right) q_{s}-f$, respectively. We can compute the equilibrium outputs as $q_{i}^{T}=$ $\left(1-2 t_{i} e_{n}+t_{j} e_{n}\right) / 3$ and the equilibrium profits as $\pi_{n}^{T}=\pi_{n}^{t}+f$ and $\pi_{s}^{T}=\pi_{s}^{t}-f$, where

$$
\pi_{i}^{t}=\left(1-2 t_{i} e_{n}+t_{j} e_{n}\right)^{2} / 9
$$

is the i-firm's market profit and hereafter we use superscripts $T$ and $t$ to denote the technology transfer. 
In the second stage, the governments choose their taxes to maximize their respective welfare, $W_{i}^{T}=\pi_{i}^{T}-D_{i}\left(q_{i}^{T} e_{n}+\gamma q_{j}^{T} e_{n}\right)+t_{i} e_{n} q_{i}^{T}$. It is easy to calculate the equilibrium taxes

$$
t_{i}^{T}=\frac{1}{5 e_{n}}\left[e_{n}(2-\gamma)\left(4 \beta_{i}-\beta_{j}\right)-1\right] .
$$

Note that $t_{n}^{T}>t_{s}^{T}$ since $\beta_{n}>\beta_{s}$. In addition, the necessary and sufficient conditions for $t_{i}^{T}>0$ are

$$
\text { C3: } \quad \frac{1+e_{n}(2-\gamma) \beta_{j}}{4 e_{n}(2-\gamma)}<\beta_{i}<\frac{4 e_{n}(2-\gamma) \beta_{j}-1}{e_{n}(2-\gamma)} \text {. }
$$

The inequalities also imply that $\beta_{i}>1 / 3 e_{n}(2-\gamma)$.

Note that the above equilibrium results can also be obtained by setting $e_{s}=e_{n}$ in the previous section. Hence, the properties of $t_{i}^{T}$ can be similarly derived and understood and condition C3 can be similarly interpreted.

Let us compare each country's equilibrium tax with technology transfer to that without technology transfer. Defining $\Delta t_{s} \equiv t_{s}^{0}-t_{s}^{T}$ and $\Delta t_{n} \equiv t_{n}^{T}-t_{n}^{0}$, we obtain

$$
\begin{aligned}
\Delta t_{s} & =\frac{1}{5 e_{n} e_{s}}\left(e_{s}-e_{n}\right)\left[2\left(\beta_{n}+2 \gamma \beta_{s}\right) e_{n}+1\right]>0 \text { and } \frac{\partial \Delta t_{s}}{\partial e_{s}}>0 \\
\Delta t_{n} & =\frac{2}{5 e_{n}}\left(e_{s}-e_{n}\right)\left(\beta_{s}+2 \gamma \beta_{n}\right)>0 \text { and } \frac{\partial \Delta t_{n}}{\partial e_{s}}>0 .
\end{aligned}
$$

Proposition 1 below and Figure 2 show the ranking of all taxes.

Proposition 1: (i) The Southern (resp. Northern) pollution tax is lower (resp. higher) with technology transfer than without, that is, $t_{s}^{T}<t_{s}^{0}$ and $t_{n}^{T}>t_{n}^{0}$. (ii) The difference between the tax with technology transfer and that without is larger for the South than for the North: $\Delta t_{s}>\Delta t_{n}$. Proof: (i) The results are obtained by directly comparing (4) and (6). (ii) Note that

$$
\Delta t_{s}-\Delta t_{n}=\frac{1}{5 e_{n} e_{s}}\left(e_{s}-e_{n}\right)\left[2\left(\beta_{n}+2 \gamma \beta_{s}\right) e_{n}+1-2\left(\beta_{s}+2 \gamma \beta_{n}\right) e_{s}\right]
$$

and so $\Delta t_{s}-\Delta t_{n}>0$ if and only if $\left(\beta_{s}+2 \gamma \beta_{n}\right) e_{s}-\left(\beta_{n}+2 \gamma \beta_{s}\right) e_{n}<1 / 2$. Since $e_{s}>e_{n}$, the LHS of this condition is less than $\left(\beta_{s}+2 \gamma \beta_{n}\right) e_{n}-\left(\beta_{n}+2 \gamma \beta_{s}\right) e_{n}=e_{n}\left(\beta_{n}-\beta_{s}\right)(2 \gamma-1) \leq 0$ since $\gamma \leq 1 / 2$.

$<$ Figure 2 about here $>$ 
Part (i) of Proposition 1 contradicts many people's perceptions because it shows that after technology transfer, the optimal pollution tax for the South becomes lower. However, using Lemma 1, we can easily understand this outcome. Technology transfer lowers $e_{s}$ and a country's tax is lower with the cleaner technology. Alternatively, one can also understand the intuition based on $\partial t_{s}^{0} / \partial e_{s}>0$ and $\partial t_{n}^{0} / \partial e_{s}<0$ (Lemma 1) or Figure 1. Part (ii) of Proposition 1 says that technology transfer lowers the South's tax more than the increase in the North's tax. As a result, the average tax rate is lower than without technology transfer. This is simply because the average technology has been improved by technology transfer.

\subsection{Equilibrium choice of technology transfer}

With the analyses in the previous two subsections, we are now ready to examine the first stage of the game regarding technology transfer.

Suppose the N-firm is willing to transfer its technology to the S-firm. Then, the two firms bargain over the price of the technology. Following Katz and Shapiro (1985), we assume that this price is a fixed fee (no royalty), $f$. Assuming that the N-firm's bargaining power is $\alpha \in(0$, 1) and that of the S-firm is $1-\alpha$, the equilibrium transfer price is given by $f^{*}=\operatorname{argmax}$ $\left(\pi_{n}^{T}-\pi_{n}^{0}\right)^{\alpha}\left(\pi_{s}^{T}-\pi_{s}^{0}\right)^{1-\alpha}$. Choosing $f$ to maximize $\left(\pi_{n}^{T}-\pi_{n}^{0}\right)^{\alpha}\left(\pi_{s}^{T}-\pi_{s}^{0}\right)^{1-\alpha}$ or, equivalently, to maximize $\alpha \ln \left(\pi_{n}^{t}+f-\pi_{n}^{0}\right)+(1-\alpha) \ln \left(\pi_{s}^{t}-f-\pi_{s}^{0}\right)$ yields the equilibrium fee

$$
f^{*}=\alpha\left(\pi_{s}^{t}-\pi_{s}^{0}\right)+(1-\alpha)\left(\pi_{n}^{0}-\pi_{n}^{t}\right) .
$$

We now show that as a result of technology transfer and the second-stage policy changes, the S-firm gains in the market (i.e., $\pi_{s}^{t}>\pi_{s}^{0}$ ) while the N-firm loses (i.e., $\pi_{n}^{0}>\pi_{n}^{t}$ ). All changes resulting from the technology transfer give rise to this market-profit redistribution. On the one hand, technology transfer lowers the S-firm's pollution content from $e_{s}$ to $e_{n}$. As a result, for the same tax rate, the S-firm pays less amount, reducing the marginal "costs". Furthermore, as

shown in Proposition 1, technology transfer induces the South to lower its tax rate from $t_{s}^{0}$ to $t_{s}^{T}$, which further reduces the S-firm's marginal "costs". On the other hand, the North raises its tax rate from $t_{n}^{0}$ to $t_{n}^{T}$, resulting in higher marginal "costs" to the N-firm. Each of these changes leads to a higher market profit for the S-firm and a lower market profit for the N-firm. Because of this redistribution of market profits, the S-firm is required to pay $\left(f^{*}>0\right)$ to the N-firm for the technology. The equilibrium fee given by (7) is chosen to cover part of the N-firm's losses 
$\left(\pi_{n}^{0}-\pi_{n}^{t}\right)$ and to share part of the S-firm's gains $\left(\pi_{s}^{t}-\pi_{s}^{0}\right)$, with the proportions determined according to their relative bargaining powers.

We now examine the conditions for technology transfer to take place. First, the S-firm is willing to pay for the Northern technology if and only if its return will be improved: $\pi_{s}^{T}-\pi_{s}^{0}>0$. Using (7), this condition is equivalent to

$$
\pi_{s}^{t}-\pi_{s}^{0}>\pi_{n}^{0}-\pi_{n}^{t} \quad \text { or } \quad \pi_{n}^{t}+\pi_{s}^{t}>\pi_{n}^{0}+\pi_{s}^{0} .
$$

The interpretation of the above condition is simple: So long as the market-profit gain by the S-firm outweighs the market-profit loss of the N-firm, or the joint market profits with technology transfer are larger than without, the S-firm is willing to pay $f^{*}$ for the technology (Tirole, 1988). Second, the N-firm is willing to transfer its technology if and only if its return will be enhanced: $\pi_{n}^{T}-\pi_{n}^{0}>0$. Using (7), we find that this condition is equivalent to (8). That is, the two firms have the same incentives to transfer the technology and the reason for this is that Nash bargaining with monetary transfer fully internalizes the negative effect on each other's payoff, resulting in the maximization of the joint profits.

Substituting in (8) with the equilibrium profits obtained from the previous two sections yields the necessary and sufficient condition for technology transfer in the first stage:

$$
t_{s}^{0}\left(e_{s}-e_{n}\right)\left(2-5 t_{s}^{0} e_{n}-5 t_{s}^{0} e_{s}+8 t_{n}^{0} e_{n}\right)+A e_{n}>0,
$$

where $A \equiv\left(\Delta t_{s}-\Delta t_{n}\right)\left[2\left(1-2 t_{s}^{0} e_{n}+t_{n}^{0} e_{n}\right)+3 e_{n}\left(\Delta t_{s}+\Delta t_{n}\right)\right]+6 e_{n}\left(t_{n}^{0}-t_{s}^{0}\right)\left(\Delta t_{s}+2 \Delta t_{n}\right)$.

\subsection{Policy adjustment and technology transfer}

We have seen in Proposition 1 how the first-stage equilibrium of the technology transfer affects the second-stage equilibrium of the pollution tax. In this subsection, we depart from the SPNE by considering an off-equilibrium case in which the governments adhere to the policies $\left\{t_{n}^{0}, t_{s}^{0}\right\}$ despite the technology transfer. The sole purpose of the off-equilibrium analysis is to examine the role of the policy adjustment in affecting technology transfer. This will also help us to understand the central issue of the present study, i.e., the interplay of MEA and technology transfer, to be analyzed in section 3 .

Recall from the analysis at the beginning of this section that both governments' policy adjustments increase the S-firm's market profits and reduce the N-firm's market profit. Based on 
the bargaining outcome (7), it must be true that the transfer fee is higher when the governments adjust their policies in response to technology transfer than when the governments keep their initial policies $\left\{t_{n}^{0}, t_{s}^{0}\right\}$ unchanged.

Note that the off-equilibrium market outcomes, in which technology transfer takes place but the policies are still $\left\{t_{n}^{0}, t_{s}^{0}\right\}$ are $q_{i}^{T 0}=\left(1-2 t_{i}^{0} e_{n}+t_{j}^{0} e_{n}\right) / 3$ and $\pi_{i}^{T 0}=\left(q_{i}^{T 0}\right)^{2}$. Substituting them into the technology transfer condition, similar to (9), we obtain the corresponding necessary and sufficient condition for technology transfer: $t_{s}^{0}\left(e_{s}-e_{n}\right)\left[2\left(q_{s}^{T 0}+q_{s}^{0}\right)-\left(q_{n}^{T 0}+q_{n}^{0}\right)\right]>0$, which can be simplified to

$$
t_{s}^{0}\left(e_{s}-e_{n}\right)\left(2-5 t_{s}^{0} e_{n}-5 t_{s}^{0} e_{s}+8 t_{n}^{0} e_{n}\right)>0
$$

Notice that by substituting $t_{i}^{0}$, the term in the second bracket of (10) is equal to $\left[7 e_{s}+5 e_{n}+\right.$ $\left.\left(74 \beta_{n}-5 \gamma \beta_{n}-40 \beta_{s}+28 \gamma \beta_{s}\right) e_{s} e_{n}+10\left(\beta_{n}+2 \gamma \beta_{s}\right) e_{n}^{2}-\left(56 \beta_{s}+37 \gamma \beta_{n}\right) e_{s}^{2}\right] / 5 e_{s}$, which is negative for sufficiently large $e_{s}$. The intuition is that when $e_{s}$ is very large, the S-firm produces very little and the N-firm is almost a monopoly in the product market. Therefore, the N-firm has no incentive to transfer technology to the S-firm because that will erode its monopoly power. ${ }^{8}$ Thus, technology transfer will not occur when the technology gap is large.

Now we compare condition (10) with condition (11). From Proposition 1(i) and $t_{n}^{0}>t_{s}^{0}$ (under C2), we note that the second term in $A$ is positive. Also note that $\left(1-2 t_{s}^{0} e_{n}+t_{n}^{0} e_{n}\right)=3 q^{T 0}$ is positive. Thus, following Proposition 1(ii), the first term in $A$ is positive since $\gamma \leq 1 / 2$. Hence, $A<0$ and we obtain the following result.

Proposition 2: Technology transfer is more likely to occur if the government in the South (resp. North) could non-cooperatively adjust its pollution tax downward (resp. upward) after technology transfer than if it could not, although the fee for technology transfer is higher in the former case.

The intuition for the result, that technology transfer is more likely to occur even though the transfer fee is higher, is as follows. Notice that Proposition 1(ii) implies $t_{n}^{0}+t_{s}^{0}>t_{n}^{T}+t_{s}^{T}$. That is, the average tax drops after the governments adjust their policies. Therefore, anticipating policy adjustment, the firms know that there is an additional gain from technology transfer

\footnotetext{
${ }^{8}$ This can be easily seen from the condition that leads to (10). When $e_{s}$ is very large, the S-firm's output is so small such that $2\left(q_{s}^{T 0}+q_{s}^{0}\right)-\left(q_{n}^{T 0}+q_{n}^{0}\right)<0$. Hence, the condition fails to hold.
} 
because technology transfer induces a reduction in the average tax, resulting in a larger total profit (the sum of the two firms' profits) for them to share.

\section{MEAs and Technology Transfer}

We use a canonical set-up for MEAs. Specifically, suppose that the North represents an MEA and we focus on the Southern government's decision about signing the existing MEA, rather than bargaining with the North to form a new MEA. This is applicable to many current MEAs, which have the principle of open-membership. Many factors can affect the government's decision. However, understanding the role of technology transfer is important. We are particularly interested in the following two questions. First, if the N-firm transfers its technology to the S-firm, will the government in the South be more or less willing to sign the MEA? In other words, does technology transfer facilitate expansion of the MEA's to include the South? Second, will the firms be more or less willing to transfer the technology in the presence of the MEA? In other words, does the participation of the South in the MEA facilitate environmental technology transfer (in the private market)?

In order to examine the above-mentioned issues, we confine our analysis to the situation in which the existing equilibrium, in the absence of an MEA, involves no technology transfer from the North to the South, i.e., condition (9) does not hold. We characterize the MEA agreement as the one that includes the following three elements: (1) the South's accession requires it to raise its tax to a pre-specified level $t^{m}>t_{s}^{0} ;(2)$ the North (the existing member of MEA) does not lower its current tax rate, $t_{n}^{0}$; and (3) there is a fixed amount of money, $R$, transferred from the North to the South. A discussion here is useful. Note that we consider a general signatory condition in the sense that the South is required to increase its environmental tax, $t^{m}$, which does not have to be equal to or greater than $t_{n}^{0}$. Since such a policy change lowers the South's welfare and raises the North's welfare because of transboundary pollution and competition in the product market, compensation from the North to the South is unavoidable. In the real world, compensation can take various forms. For simplicity, we consider only lump-sum monetary compensation, captured by $R .^{9}$ As mentioned earlier, since we do not allow the South to bargain with the North, both

\footnotetext{
${ }^{9}$ In the real world, there are other forms of 'bribes' to induce the South to sign MEAs. As also discussed earlier, some MEAs use trade measures as such "carrots" and "sticks". It is not the purpose of this present paper, however, to take part in this discussion.
} 
$t^{m}$ and $R$ are assumed to be non-negotiable constants. ${ }^{10}$

\subsection{Will technology transfer increase the South's incentive to sign the MEA?}

It is a common view that less-developed countries would be more likely to sign MEAs to increase their environmental standards if they could gain access to the better environmental technology from the developed countries. However, little attention has been paid to a possible outcome implied by our analysis in the previous section, namely, that technology transfer could actually make it less likely for the South to sign the MEA. Specifically, Proposition 1 says that the Southern government has an incentive to lower, rather then raise, its pollution tax after its firm has acquired the better environmental technology from the North. Since the South's optimal pollution tax $\left(t_{n}^{T}\right)$ moves further below the MEA level $t^{m}$, it seems that technology transfer would reduce the South's incentives to sign the MEA.

That said, how can we make any sense out of the common view? To answer this question, we need a rigorous comparison of the South's welfare levels in different situations. It will be shown that technology transfer can either increase or decrease the South's incentive to sign the MEA. Notice that with the game specified earlier, there are potentially three cases regarding the South's decision about signing the MEA. Case 1: it signs the MEA with or without technology transfer in the first stage; Case 2: it does not sign the MEA with or without technology transfer in the first stage; and Case 3: it signs the MEA if and only if there is technology transfer in the first stage. From the MEA agreement for the South, it is quite obvious that, for a sufficiently large $R$, Case 1 will be the result and, for a sufficiently small $R$, Case 2 will be the result. Technology transfer does not affect the South's decision in both cases. Since we are more interested in the role of technology transfer, Case 3 is the focus of the analysis below.

Notice that if the Southern government signs the MEA without technology transfer, its welfare is

$$
W_{s}^{m 0}\left(t^{m}\right)=\pi_{s}^{m}-\beta_{s}\left(q_{s}^{m} e_{s}+\gamma q_{n}^{m} e_{n}\right)+t^{m} q_{s}^{m} e_{s}+R
$$

where $q_{s}^{m}=\left(1-2 t^{m} e_{s}+t_{n}^{0} e_{n}\right) / 3, q_{n}^{m}=\left(1-2 t_{n}^{0} e_{n}+t^{m} e_{s}\right) / 3$, and $\pi_{s}^{m}=\left(q_{s}^{m}\right)^{2}$. Note that the South's welfare is a function of the Southern tax $\left(t^{m}\right)$ and the Northern tax as well. In this

\footnotetext{
${ }^{10} \mathrm{~A}$ reason for such an assumption is that we are more interested in the other factor that also affects the Southern government's decision: technology transfer. It is obvious that the Southern government is more willing to accept the agreement if $R$ is greater and $t^{m}$ is smaller (closer to $t_{s}^{0}$ ).
} 
case the Northern government will have to keep its tax unchanged at $t_{n}^{0}$ after the South signs the MEA and so we simply drop it from the expression. To see why the Northern government does not alter its tax in response to the South's move, recall that without technology transfer and in the absence of an MEA, the equilibrium taxes are $\left\{t_{n}^{0}, t_{s}^{0}\right\}$. The MEA requires that the South raise its tax up to $t^{m}$. Since the two policies are strategic substitutes $\left(\partial t_{n} / \partial t_{s}<0\right)$, it is optimal for the Northern government to lower its tax. But the MEA constrains the Northern government from lowering its tax. Therefore, the constrained equilibrium taxes are $\left\{t_{n}^{0}, t^{m}\right\}$.

Now suppose technology transfer occurs in the first stage and the South decides to sign the MEA. Then, what is the Northern government's optimal choice for the pollution tax? From Lemma 1, notice that there are two opposite forces if the North could adjust its policy. On the one hand, a better environmental technology for the South induces the North to increase its pollution tax because of a reduction of the "carbon-leakage" effect. On the other hand, the increase of the pollution tax in the South (from $t_{s}^{0}$ to $t^{m}$ ) induces the North to lower its pollution tax because of the strategic effect in the product market. From (3) the Northern government's policy reaction curve with technology transfer is $t_{n}\left(t_{s}\right)=\left[3 e_{n}(2-\gamma) \beta_{n}-e_{n} t_{s}-1\right] / 4 e_{n}$. When the South raises its tax to the MEA-specified level, $t^{m}$, it is optimal for the North to set $t_{n}^{m} \equiv$ $\left[3 e_{n}(2-\gamma) \beta_{n}-e_{n} t^{m}-1\right] / 4 e_{n}$. There are two possibilities, either $t_{n}^{m} \leq t_{n}^{0}$ or $t_{n}^{m}>t_{n}^{0}$, depending on which of the two forces is dominant.

Although the MEA does not forbid the North to raise its tax, in this subsection we shall derive our results using the first case in which $t_{n}^{m} \leq t_{n}^{0}$. In light of the MEA constraint, the North does not lower but keeps its pollution tax at $t_{n}^{0}$. In this case, the South's welfare is

$$
W_{s}^{m T}\left(t^{m}\right)=\pi_{s}^{m t}-f^{m}-\beta_{s}\left(q_{s}^{m t} e_{n}+\gamma q_{n}^{m t} e_{n}\right)+t^{m} q_{s}^{m t} e_{n}+R,
$$

where $q_{s}^{m t}=\left(1-2 t^{m} e_{n}+t_{n}^{0} e_{n}\right) / 3, q_{n}^{m t}=\left(1-2 t_{n}^{0} e_{n}+t^{m} e_{n}\right) / 3, \pi_{s}^{m t}=\left(q_{s}^{m t}\right)^{2}$, and the license fee, $f^{m}=\alpha\left(\pi_{s}^{m t}-\pi_{s}^{0}\right)+(1-\alpha)\left(\pi_{n}^{0}-\pi_{n}^{m t}\right)$, where $\pi_{n}^{m t}=\left(q_{n}^{m t}\right)^{2}$ is the N-firm's market profit in the case of technology transfer and the South signing the MEA. The condition $t_{n}^{m} \leq t_{n}^{0}$ implies $t^{m} \geq\left[3 e_{n}(2-\gamma) \beta_{n}-4 e_{n} t_{n}^{0}-1\right] / e_{n}$. That is, there is a minimum level of $t^{m}$. Violation of this requirement, however, will not affect the main results for the rest of this paper. We discuss this after we obtain the main results (see footnotes 11 and 12).

The South's welfare in the case of not signing the MEA has been analyzed before. If there 
is no technology transfer, the welfare is $W_{s}^{0}\left(t_{s}^{0}\right)=\pi_{s}^{0}-\beta_{s}\left(q_{s}^{0} e_{s}+\gamma q_{n}^{0} e_{n}\right)+t_{s}^{0} q_{s}^{0} e_{s}$, where the Northern tax is $t_{n}^{0}$, and if there is technology transfer, the welfare is $W_{s}^{T}\left(t_{s}^{T}\right)=\pi_{s}^{T}-\beta_{s}\left(q_{s}^{T} e_{s}+\right.$ $\left.\gamma q_{n}^{T} e_{n}\right)+t_{s}^{T} q_{s}^{T} e_{s}$, where the Northern tax is $t_{n}^{T}$.

With the above preparation, we are now ready to derive conditions for the South to sign the MEA, in the case of technology transfer and in the case of no technology transfer, respectively.

Lemma 2: (i) Suppose there is no technology transfer in the first stage. Then, the South does not sign the $M E A$ if and only if

$$
\Delta W_{s}^{0} \equiv \frac{2}{9} e_{s}^{2}\left(t^{m}-t_{s}^{0}\right)^{2}>R
$$

(ii) Suppose there is technology transfer in the first stage. Then, the South signs the MEA if and only if

$$
\Delta W_{s}^{T} \equiv \frac{2 e_{n}^{2}}{9}\left(t^{m}-t_{s}^{T}\right)^{2}+\frac{e_{n}}{9}\left(t_{n}^{T}-t_{n}^{0}\right)\left[2+\left(t_{n}^{0}+t_{n}^{T}-t^{m}\right) e_{n}-3 \beta_{s} e_{n}(1-2 \gamma)\right] \leq R
$$

Proof: See Appendix (i).

In (13), $\Delta W_{s}^{0}$ is the South's welfare reduction (excluding compensation $R$ ) from signing the MEA. Clearly, this reduction is larger for a higher $t^{m}$ since the MEA-specified tax rate, $t^{m}$ would deviate further away from the South's optimal tax level, $t_{s}^{0}$, making the South less likely to sign the MEA (i.e., inequality (13) is less likely to hold). It is worth pointing out that the first term in $\Delta W_{s}^{T}$ of (14) corresponds to $\Delta W_{s}^{0}$ of (13), with the same interpretation, but $\Delta W_{s}^{T}$ has an extra term. That term contains $t_{n}^{0}$ because even if technology transfer takes place, the North still sets $t_{n}^{0}$ rather than $t_{n}^{T}$, provided that the South adopts the MEA level $t^{m}$. Should the North switch from $t_{n}^{0}$ to $t_{n}^{T}$, it is easy to see that this extra term will vanish. Even including this extra term, we still have $\partial \Delta W_{s}^{T} / \partial t^{m}=\left(e_{n}^{2} / 9\right)\left[4\left(t^{m}-t_{s}^{T}\right)-\left(t_{n}^{T}-t_{s}^{0}\right)\right]>0$, for $\gamma \leq 1 / 2$, because $t^{m}-t_{s}^{T}>\Delta t_{s}$ and, by Proposition 1(ii), $\Delta t_{s}>\Delta t_{n}$. That is, the South is less likely to sign the MEA if $t^{m}$ increases.

If both conditions (13) and (14) are satisfied, then the Southern government does not want to sign the MEA without technology transfer but it does with technology transfer. When this occurs, we say that the Southern government's incentive compatibility (or GIC in short) condition is satisfied. Based on Lemma 2, there exists a monetary transfer, $R$, such that the GIC condition 
holds (i.e., both inequalities (13) and (14) hold) if and only if $\Delta W_{s}^{0}$ is greater than $\Delta W_{s}^{T}$. As we are less interested in the size of $R$ but other parameters, we simply state the GIC condition as

$(\mathbf{G I C}): \quad 2 e_{s}^{2}\left(t^{m}-t_{s}^{0}\right)^{2}-2 e_{n}^{2}\left(t^{m}-t_{s}^{T}\right)^{2}-e_{n}\left(t_{n}^{T}-t_{n}^{0}\right)\left[2+\left(t_{n}^{0}+t_{n}^{T}-t^{m}\right) e_{n}-3 \beta_{s} e_{n}(1-2 \gamma)\right]>0$

Therefore, if this GIC condition is satisfied, the South will sign the MEA with technology transfer but will not sign without technology transfer. That is,

Proposition 3: Technology transfer facilitates the South's participation in the MEA if and only if the GIC condition holds.

Since after technology transfer, the South's optimal level of pollution tax is further below $t^{m}$ (Proposition 1), we can easily understand why technology transfer may not facilitate the South's MEA participation. Let us therefore focus our discussion on the less obvious possibility. The key to understanding the possibility that technology transfer facilitates the South's MEA participation is to realize that the South's welfare is a function of its environmental technology and, more importantly, that the shape of the function changes with the environmental technology it uses. As shown in Figure 3, with better technology, the shape of the South's welfare function is flatter, reflecting the fact that the cost of increasing the pollution tax is lower. The converse is true with a less-efficient environmental technology.

\section{$<$ Figure 3 about here $>$}

Figure 3 illustrates the South's welfare under various situations. The North's compensation shifts the South's welfare curve $\left(W_{s}^{0}\left(t_{s} ; t_{n}=t_{n}^{0}\right)\right.$ in the case of no technology transfer and $W_{s}^{T}\left(t_{s} ; t_{n}=t_{n}^{0}\right)$ in the case of technology transfer) up in parallel by a distance equal to $R$. First, compared with $t_{s}^{0}$, the South's optimal tax in the case of technology transfer $\left(t_{s}^{0}\right)$ is further away from the MEA-specified level, $t^{m}$, suggesting that the South should have a smaller incentive to increase its tax to $t^{m}$ when there is technology transfer. Second, when the South sign the MEA, the Northern government chooses $t_{n}^{0}$, which is lower than $t_{n}^{T}$ if the South does not sign the MEA. This lower tax in the North reduces the South's welfare and thus also reduces the South's incentive to sign the MEA. However, as shown in Figure 3, the South's welfare curve in the case 
of technology transfer is flatter than that without technology transfer. Hence, welfare reduction when $t_{s}$ departs from its optimal level is less severe in the case of technology transfer than in the case of no technology transfer. When this effect is dominant, it gives rise to the result that the technology transfer increases the South's incentive to sign the MEA. ${ }^{11}$ In subsection 3.3 we will use a specific example to show that the GIC condition does hold for some particular values.

In summary, technology transfer could either increase or reduce the South's incentive to sign an MEAs.

At the end of this subsection, we use our analysis and the result obtained so far to examine another interesting and widely debated issue when the South claims that it is not willing to strengthen its environmental protection policies unless the North transfers a good technology to the South. To this end, we once more deviate from our basic model by giving the Southern government an opportunity to announce its intention (not commitment) to sign the MEA before the firms make their technology transfer decision. Proposition 4 certainly lends support for such a claim. However, when the GIC condition fails to hold, it is doubtful that the Southern government will commit to its announcement. When the GIC condition fails, we have $\Delta W_{s}^{0}<$ $\Delta W_{s}^{T}$. If compensation $R$ is not sufficiently great (when $R<\Delta W_{s}^{0}$ ), the South will not sign the MEA because there is no technology transfer. But, if the North transfers its technology to the South, the South will have even a smaller incentive to sign the MEA because for the same compensation, the welfare loss from signing the MEA now is greater than in the case of no technology transfer $\left(R<\Delta W_{s}^{T}\right)$. Therefore, the South may anticipate the benefit from technology transfer and so announces its intension to sign the MEA, if by doing so it can induce technology transfer. But there is a time consistency problem. In this case, becoming a signatory should be a pre-requirement for a country in the South to receive assisted technology transfer by other MEA signatories.

\subsection{Will the South's participation in the MEA facilitate technology transfer?}

\footnotetext{
${ }^{11}$ Note that in the case of $t_{n}^{m}>t_{n}^{0}$, we can derive a similar GIC condition and so Proposition 3 applies. Also note that the central point addressed in this section is that the GIC condition holds for some parameter values and, hence, technology transfer does facilitate the South's decision to sign of the MEA. In the case of $t_{n}^{m}>t_{n}^{0}$, the South's welfare would be greater than if the North is forced to set its tax at $t_{n}^{0}$, since a higher tax in the North benefits the N-firm (strategic reason) and the South's population (transboundary pollution). Therefore, the South's welfare reduction, $\Delta W_{s}^{T}$, would be smaller, making the GIC condition more likely to hold. In sum, the case of $t_{n}^{m}>t_{n}^{0}$ reinforces the conclusion obtained in this section.
} 
Proposition 2 has shown that governments' responses to technology transfer affect the market incentive for technology transfer. Since the South's MEA participation requires it to increase its environmental tax, Proposition 2 seems to suggest that the MEA may reduce the market incentive for environmental technology transfer. We will show in this subsection that this is exactly the case.

First, if the firms anticipate that the Southern government will not sign the MEA, they will not transfer the technology if condition (9) fails to hold.

Similar to condition (8), we can derive the condition for technology transfer when the firms anticipate that the Southern government will sign the MEA: the sum of the two firms' profits when there is technology transfer and when the South signs the MEA is greater than that when there is no technology transfer and the South does not sign the MEA, i.e., $\pi_{n}^{m t}+\pi_{s}^{m t}>\pi_{n}^{0}+\pi_{s}^{0}$. Substituting in the profit functions, this condition reduces to

$$
\left(t_{s}^{0} e_{s}-t^{m} e_{n}\right)\left(2-5 t^{m} e_{n}-5 t_{s}^{0} e_{s}+8 t_{n}^{0} e_{n}\right)>0
$$

From the discussion after (10) we note that the second bracket will be negative if $e_{s}$ becomes sufficiently large, and so condition (15) puts an upper bound on $e_{s}$. However, the condition also puts a lower bound on $e_{s}$. For small $e_{s}$, such that the second bracket is positive, the first bracket should also be positive, which in turn implies that $e_{s}$ cannot be too close to $e_{n}$ because $t_{s}^{0}<t^{m}$ and $t_{s}^{0}$ increases with $e_{s}$.

We say that the technology transfer incentive compatibility (TIC in short) condition is satisfied when (9) fails to hold but (15) holds. Then, when the TIC condition holds, the firms transfers the technology if and only if they anticipate that the South will sign the MEA. If this occurs and the Southern government signs the MEA, then we can say that the MEA facilitates technology transfer. Using (??) and (15), we can simplify the TIC condition to

$$
(\mathbf{T I C}): \quad\left(t^{m}-t_{s}^{0}\right)\left[5 e_{n}\left(t^{m}+t_{s}^{0}\right)-8 e_{n} t_{n}^{0}-2\right]-A>0
$$

Proposition 4: The TIC condition never holds. That is, the MEA does not facilitate technology transfer in the private market. 
Proof: See Appendix (ii). ${ }^{12}$

Since the firms' technology transfer incentive depends on the comparison of the total profits with and without technology transfer in various cases, we should examine how the joint profit changes in order to understand why the MEA does not facilitate technology transfer. If the firms do not have any incentive to transfer the technology when there is no MEA, it must be the case that their joint market-profit after technology transfer is lower than before, i.e., $\pi_{n}^{t}+\pi_{s}^{t}<\pi_{n}^{0}+\pi_{s}^{0}$. The joint market profits with technology transfer are determined by the policy levels, $t_{n}^{T}$ and $t_{s}^{T}$. If the South signs the MEA, the joint market profits, $\pi_{n}^{m t}+\pi_{s}^{m t}$, will be determined by the policy levels, $t_{n}^{0}$ and $t^{m}$. Since the average tax in the case of MEA $\left(\left(t_{n}^{0}+t^{m}\right) / 2\right)$ is higher than the average tax in the case of no MEA $\left(\left(t_{n}^{T}+t_{s}^{T}\right) / 2\right)$, the joint profit will be much lower after technology transfer in the case of the South signing of the MEA. Hence, the MEA lowers the firms' incentive to transfer technology.

Recall that at the end of the preceding subsection, we argue that, under certain circumstances, the South's pre-commitment to sign the MEA is necessary to induce technology transfer. However, Proposition 4 shows that such a pre-commitment is not sufficient. This result, though somewhat pessimistic, does generate a useful policy implication: Monetary transfer or subsidy should be directed to the firms involved in technology transfer. Monetary transfer is made from the Northern to the Southern government to compensate the latter for raising its pollution tax. The S-firm suffers from a higher tax, but it is one of the players making the technology transfer decision. Hence, without appropriate compensation using the transfered money, $R$, the S-firm will not implement technology transfer. This provides a strong support to the argument that in addition to monetary transfer, MEAs should allow the Southern government to subsidize (or, more generally, assist) its firms for environmental technology transfer. This policy implication in fact is consistent with the existing WTO rules that allow subsidies to facilitate adaptation of new environmental technology and regulations (e.g., see Hoekman and Kostecki, 1995, pp.104-109).

\subsection{A numerical example}

\footnotetext{
${ }^{12}$ The proof contains the case of $t_{n}^{m}>t_{n}^{0}$. Thus, the proposition holds regardless of whether the Northern government sets $t_{n}^{m}=t_{n}^{0}$ or $t_{n}^{m}>t_{n}^{0}$, with technology transfer and the South's MEA membership.
} 
In this section, we provide a numerical example for the results of Proposition 3 that technology transfer could either reduce or increase the South's incentive to sign the MEA. Specifically, we will show the GIC condition could either hold or not hold, depending upon the environmental technology gap, $e_{s}-e_{n}$.

To obtain numerical results, we have to choose values for a set of parameters in the model. First, we normalize $e_{n}=1$. As a result, $e_{s}$ (or $\left.e_{s}-1\right)$ captures the technology gap. Second, we pick $\beta_{n}=1 / 3$ to avoid the disutility of the pollution being so severe to create negative welfare. Third, we choose $\gamma=1 / 4$ in accordance with the assumption that the degree of transboundary pollution is not very large. The values for the rest of the parameters $\left(\beta_{s}\right.$ and $\left.e_{s}\right)$ will be chosen to satisfy assumptions C1-C3.

Notice that $\mathrm{C} 1$ (ii) requires $\beta_{s}>1 / 3\left(2 e_{s}-\gamma e_{n}\right)=4 / 3\left(8 e_{s}-1\right)$, which implies $\beta_{s}>4 / 21$ for $e_{s}$ being sufficiently close to 1 . Therefore, we choose $\beta_{s}=5 / 21$, which will give us some room to vary $e_{s}$. Finally, recall from Lemma $1, \partial t_{n}^{0} / \partial e_{s}<0$ and $\partial t_{s}^{0} / \partial e_{s}>0$. Hence, we need to impose an upper bound on $e_{s}$ to ensure $\mathrm{C} 2$, i.e., $t_{n}^{0}>t_{s}^{0}$. Given the above specifications on all parameters other than $e_{s}$, we have $t_{n}^{0}=\left(145-68 e_{s}\right) / 420$ and $t_{s}^{0}=\left(167 e_{s}-160\right) / 420 e_{s}$. Then, C2 suggests $34 e_{s}^{2}+11 e_{s}-80<0$, which implies $e_{s} \leq 1.38$.

In summary, we assume

$$
e_{n}=1, \quad \gamma=\frac{1}{4}, \quad \beta_{n}=\frac{1}{3}, \quad \beta_{s}=\frac{5}{21} \text { and } e_{s} \in(1,1.38]
$$

Conditions C1-C3 are all satisfied under (17). Using this specification, we obtain $t_{n}^{T}=11 / 60$ and $t_{s}^{T}=1 / 60$ and, thus, the GIC condition becomes,

$$
G \equiv\left[280\left(210 t^{m}-167\right) t^{m}+10067\right] e_{s}^{2}+120\left(413 t^{m}-241\right) e_{s}+\left[18853+2800\left(21 t^{m}-1\right) t^{m}\right]>0 .
$$

Therefore, we obtain the following result.

Proposition 5: Suppose the model is specified by parameterization (17). Then, for any given $t^{m} \in\left(t_{s}^{0}, t_{n}^{0}\right)$, we have $\partial G / \partial e_{s}<0$. In the case of $t^{m}=0.12$ in $G$, we have $G>0$ for $e_{s}<1.146$ and $G<0$ for $e_{s} \in(1.146,1.38)$.

Proof: See Appendix (iii). 
Proposition 5 indicates that technology transfer will facilitate the South's decision to sign the MEA if and only if the technology gap is not too wide. Finally, let us provide the intuition for the important role of the technology gap, or the result $\partial G / \partial e_{s}<0$. We have known that the only reason that the South is not willing to sign the MEA even after technology transfer is that its optimal policy level $\left(t_{s}^{T}\right)$ departs further away below the MEA-level $\left(t^{m}\right)$. This policy gap $\left(t^{m}-t_{s}^{T}\right)$ is larger when the technology gap is larger. Hence, technology transfer can induce the South to sign the MEA when the technology gap is small because the targeted level is not too far away from its optimal level and the monetary transfer is large enough to compensate for this loss.

\section{Concluding Remarks}

This paper develops a model to investigate formally the relationship between environmental technology transfer and the South's participation in MEAs, in light of the commonly shared view that developing countries may not be able to afford to raise their environmental standards given their existing technologies. We have shown that environmental technology transfer could either increase or reduce the South's incentives to sign the MEA. On the other hand, the South's commitment to sign the MEA would reduce the market incentive for technology transfer.

Our model can be extended to reanalyze the issues considered in the present paper as well as other related issues. For example, one can introduce pollution abatement technologies, available in the North, and examine transfer of this type of technology. Instead of pollution tax, we can also examine the case in which the governments and MEAs choose to legislate/enforce environmental standards. The issue regarding developed countries' incentives to include developing countries in existing MEAs is also interesting.

\section{Appendix}

(i) Proof of Lemma 2:

First, note that for any quadratic function $f(x)=a x^{2}+b x+c$, if $x_{0}$ is the point for maximum or minimum $f(x)$, then 


$$
f(x)-f\left(x_{0}\right)=a\left(x-x_{0}\right)^{2}
$$

Lemma 2(i). Define $W_{a}(t) \equiv\left(1-2 e_{s} t+e_{n} t_{n}^{0}\right)^{2} / 9-\beta_{s}\left[\left(1-2 e_{s} t+e_{n} t_{n}^{0}\right) e_{s}+\gamma(1-\right.$ $\left.\left.2 e_{n} t_{n}^{0}+e_{s} t\right) e_{n}\right] / 3+t\left(1-2 e_{s} t+e_{n} t_{n}^{0}\right) e_{s} / 3$, which is a quadratic function of $t$. Then, we have $W_{s}^{0}\left(t_{s}^{0}\right)=W_{a}\left(t_{s}^{0}\right)$ and $W_{0}^{m}\left(t^{m}\right)=W_{a}\left(t^{m}\right)+R$. Moreover, $t_{s}^{0}$ is the optimal point of $W_{a}(t)$. Hence, using (A1) we obtain

$$
W_{0}^{m}\left(t^{m}\right)-W_{s}^{0}\left(t_{s}^{0}\right)=\left(\frac{4}{9} e_{s}^{2}-\frac{2}{3} e_{s}^{2}\right)\left(t^{m}-t_{s}^{0}\right)^{2}+R=-\frac{2}{9} e_{s}^{2}\left(t^{m}-t_{s}^{0}\right)^{2}+R .
$$

The necessary and sufficient condition (13) follows.

Lemma 2(ii). Define $W_{b}(t) \equiv\left(1-2 t e_{n}+t_{n}^{T} e_{n}\right)^{2} / 9-f^{m}-\beta_{s} e_{n}\left[\left(1-2 t e_{n}+t_{n}^{T} e_{n}\right)+\gamma(1-\right.$ $\left.\left.2 t_{n}^{T} e_{n}+t e_{n}\right)\right] / 3+t e_{n}\left(1-2 t e_{n}+t_{n}^{T} e_{n}\right) / 3$, which is a quadratic function of $t$. Also define $W_{b 1}(t)$ as the same as $W_{b}(t)$ except that $t_{n}^{T}$ in $W_{b}(t)$ is replaced by $t_{n}^{0}$. Then, we have $W_{s}^{T}\left(t_{s}^{T}\right)=W_{b}\left(t_{s}^{T}\right)$ and $W_{t}^{m}\left(t^{m}\right)=W_{b 1}\left(t^{m}\right)+R$. Moreover, $t_{s}^{T}$ is the optimal point of $W_{b}(t)$. Hence, using (A1) we obtain

$$
W_{b}\left(t^{m}\right)-W_{b}\left(t_{s}^{T}\right)=\left(\frac{4}{9} e_{n}^{2}-\frac{2}{3} e_{n}^{2}\right)\left(t^{m}-t_{s}^{T}\right)^{2}=-\frac{2 e_{n}^{2}}{9}\left(t^{m}-t_{s}^{T}\right)^{2}
$$

With some calculation, we also have

$$
W_{b 1}\left(t^{m}\right)-W_{b}\left(t^{m}\right)=\frac{e_{n}}{9}\left(t_{n}^{0}-t_{n}^{T}\right)\left[2+\left(t_{n}^{0}+t_{n}^{T}-t^{m}\right) e_{n}-3 \beta_{s} e_{n}(1-2 \gamma)\right] .
$$

Hence, $W_{t}^{m}\left(t^{m}\right)-W_{b}\left(t_{s}^{T}\right)=W_{b 1}\left(t^{m}\right)-W_{b}\left(t_{s}^{T}\right)+R$, and, using the above expressions, we obtain condition (14).

(ii) Proof of Proposition 4:

First, by Proposition 1(ii), $A>0$ for $\gamma \leq 1 / 2$. Second, since $t_{s}^{0}<t^{m} \leq t_{n}^{0}$, we have $5 e_{n}\left(t^{m}+t_{s}^{0}\right)-8 e_{n} t_{n}^{0}-2<5 e_{n}\left(t_{n}^{0}+t_{n}^{0}\right)-8 e_{n} t_{n}^{0}-2=2\left(e_{n} t_{n}^{0}-1\right)<0$. The last equality holds because $p-e_{n} t_{n}^{0}>0$ (for the $\mathrm{N}$-firm to make any profit) and $p<1$ (because the demand function is assumed as $\left.p=1-\left(q_{n}+q_{s}\right)\right)$. Thus, the TIC condition fails to hold.

We now turn to see if the proposition holds when the Northern government sets its tax at $t_{n}^{m}>t_{n}^{0}$ with technology transfer and the South's MEA participation. In this case, the average tax is $\left(t^{m}+t_{n}^{m}\right) / 2$, which is greater than the average tax when the Northern government fixes 
its tax at $t_{n}^{0}$. Thus, the resulting total market profit is lower, reducing the firms' technology transfer incentive. The TIC condition fails to hold.

(iii). Proof of Proposition 5:

From (18) we have $\partial G / \partial e_{s}=2\left[G_{1} e_{s}+60\left(413 t^{m}-241\right)\right]$, where $G_{1} \equiv 280\left(210 t^{m}-167\right) t^{m}+$ 10067. Setting $\mathrm{d} G_{1} / \mathrm{d} t^{m}=117600 t^{m}-46760=0$, we note that $G_{1}$ reaches its minimum at $t^{m}=1169 / 2940 \approx 0.4$. However, even at $t^{m}=0.4, G_{1}=771$. Thus, $G_{1}>0$ for all $t^{m}$. This result, together with the constraint on $e_{s}(\leq 1.38)$, implies $\partial G / \partial e_{s} \leq 2\left[1.38 G_{1}+\right.$ $\left.60\left(413 t^{m}-241\right)\right]=2 G_{2}\left(t^{m}\right)$, where $G_{2}\left(t^{m}\right) \equiv 81144\left(t^{m}\right)^{2}-36008 t^{m}-4393$. Given $t^{m}>0$, the point for $G_{2}\left(t^{m}\right)=0$ is $t^{m} \approx 0.543$. Hence, $G_{2}\left(t^{m}\right)<0$ for $t^{m}<0.543$. Note that $t_{n}^{0}=\left(145-68 e_{s}\right) / 420<(145-68) / 420<0.184$ for all $e_{s}$ and $t^{m}<t_{n}^{0}$. Therefore, $G_{2}\left(t^{m}\right)<0$ and the result $\partial G / \partial e_{s}<0$ follows.

\section{References}

[1] Barrett, Scott (1994a), "Strategic environmental policy and international trade", Journal of Public Economics 54, 325-38.

[2] Barrett, Scott (1994b), "Self-Enforcing International Environmental Agreements" Oxford Economic Papers 46, 878-894.

[3] Barrett, Scott (1997a), "Towards a theory of international environmental cooperation" in New Directions in the Economics of the Environment edited by Carlo Carraro and Domenico Siniscalco, Cambridge University Press: London

[4] Barrett, Scott (1997b), "The strategy of trade sanctions in international environmental agreements", Resource and Energy Economics 19, 345-61.

[5] Bhagwati, Jagdish and Robert E. Hudec (1996), Fair Trade and Harmonization, volumes 1 and 2, The MIT Press: London.

[6] Carraro, C.and D. Siniscalco (1993), "Strategies for the international protection of the environment", Journal of Public Economics 52, 309-28.

[7] Carraro, C.and D. Siniscalco (1994), "Transfers and commitments in international negotiations", in International Environmental Problems, Kluwer Academic Publishers, London

[8] Charnovitz, Steve (1993), "Environmental harmonization and trade policy", in Trade and the Environment: Law, Economics, and Policy 282 edited by D. Zaelke, P. Orbuch and R.F. Housman. 
[9] Conrad, K.(1996), "Optimal environmental policy for oligopolistic industries under intraindustry trade" in Environmental Policy and Market Structure edited by C. Carraro, Y. Katsoulacos, and A. Xepapadeas, Kluwer Academic Publishers, London.

[10] Heal, G. (1993), "Formation of international environmental agreements" in Trae, Innovation, Environment, edited by C. Carraro, Kluwer Academic Publishers: London.

[11] Hoekman, M. Bernard and Michel M. Kostecki (1995), The Political Economy of the World Trading System, Oxford University Press: Oxford.

[12] Hoel, M. (1992), "Emission taxes in a dynamic international game of $\mathrm{CO}_{2}$ Emissions" in Conflicts and Cooperation in Managing International Environmental Resources edited by R. Pethig, Springer-Verlag, Berlin.

[13] Hudec, Robert, E. (1996), "GATT legal restraints on the use of trade measures against foreign environmental practices", in Fair Trade and Harmonization (volume 2), edited by Jagdish Bhagwati and Robert E. Hudec, The MIT Press: London.

[14] Katz, M. and C. Sharpiro (1985), "On the licensing of innovations", Rand Journal of Economics 16, 504-20.

[15] Kennedy, P.(1994), "Equilibrium pollution taxes in open economies with imperfect competition", Journal of Environmental Economics and Management 27, 49-63.

[16] Neary, J. Peter (1994), "Cost asymmetries in international subsidy games: Should governments help winners or losers?", Journal of International Economics 37, 197-218.

[17] Tirole, Jean (1988), The Theory of Industrial Organization, MIT Press: Mass. Cambridge.

[18] Ulph, Alistair (1996), "Environmental policy and international trade when governments and producers act strategically", Journal of Environmental Economics and Management $30,265-81$.

[19] UNEP and IISD (2000), Environment and Trade: A Handbook, The United Nations Environmental Programme (UNEP) and the International Institute for Sustainable Development (IISD).

[20] WTO (1996), Report of the CTE, Committee on Trade and Environment, the World Trade Organization, 12 November 1996. 


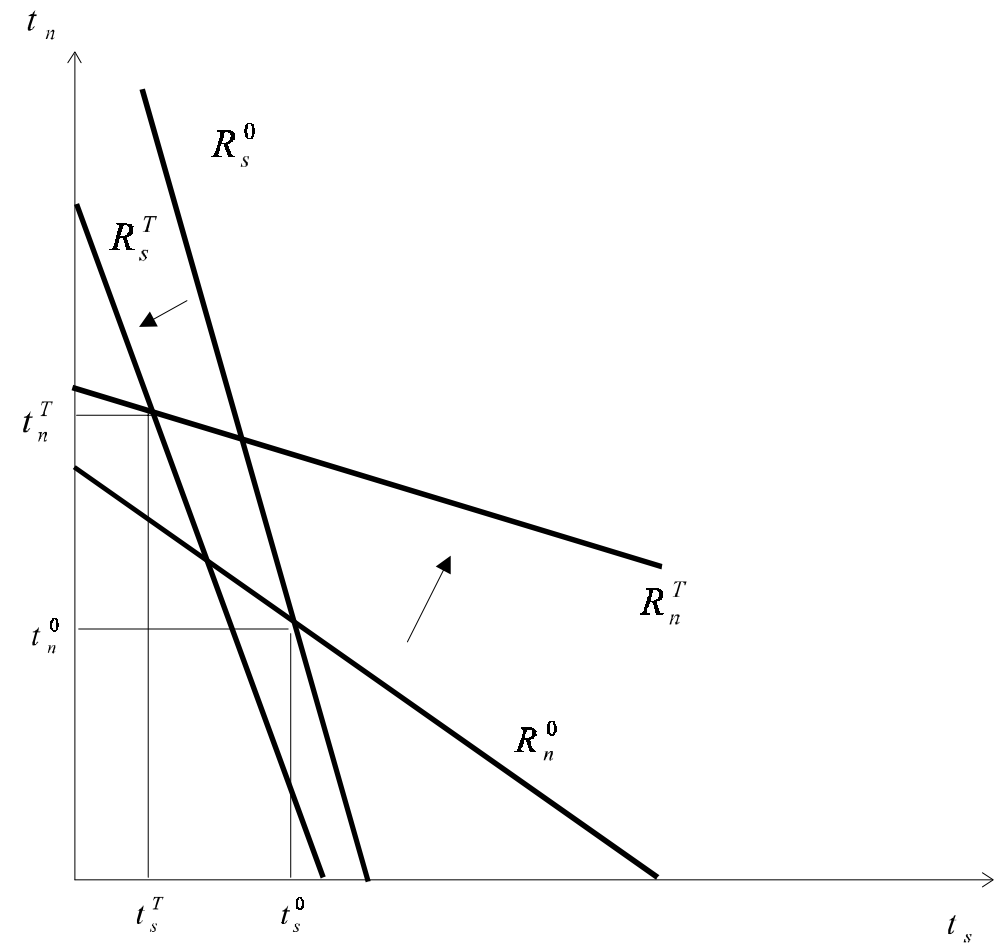

Figure 1: Policy reaction curves

Figure 1: 


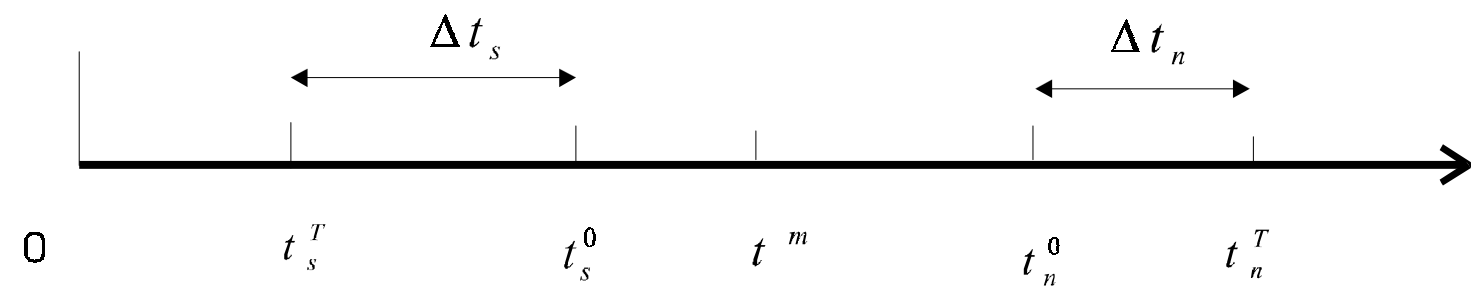

Figure 2: Equilibrium tax policies in the two regions

Figure 2: 


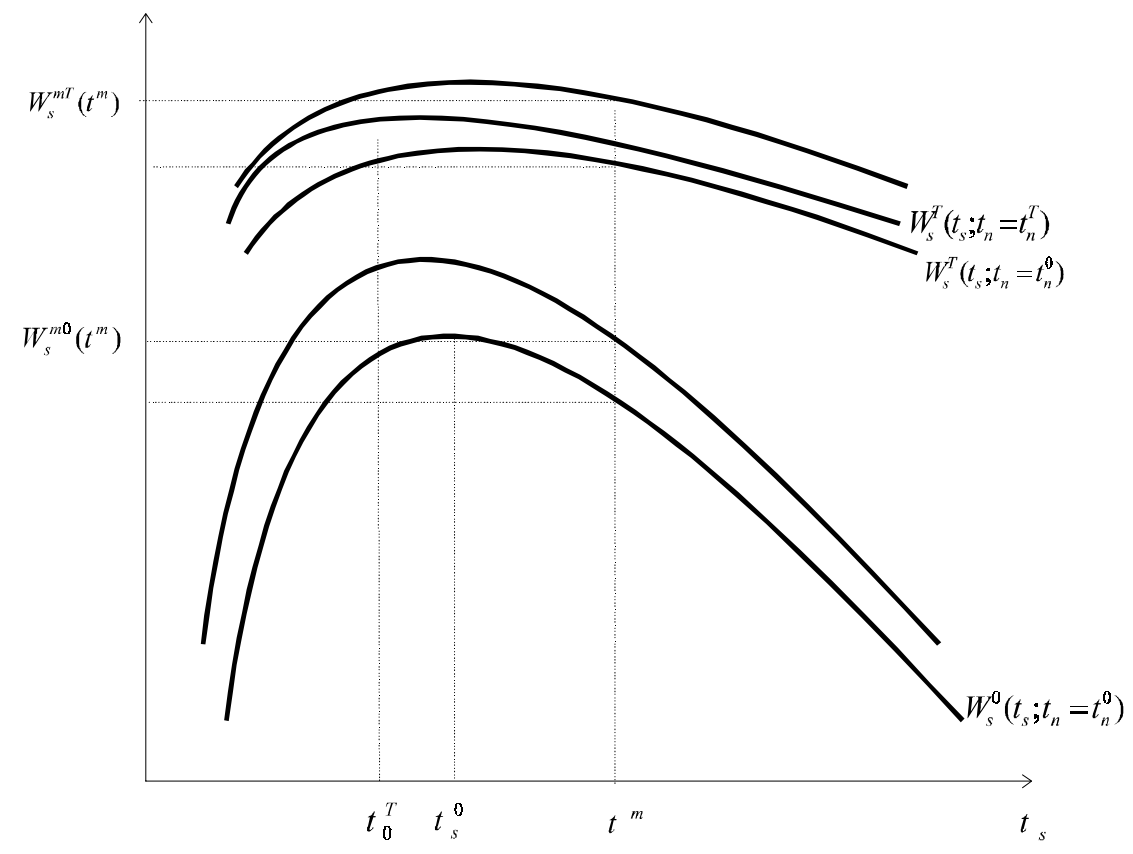

Flgure 3: South's Incentlve to Joln the MEA

Figure 3: 